\title{
Hacia un análisis sistémico del proceso probatorio en materia de asilo por motivo de orientación sexual e identidad de género en el derecho común europeo
}

\author{
Towards a Systemic Analysis of the Evidence \\ Assessment in Asylum Claims on the Basis \\ of Sexual Orientation and Gender Identity \\ in the Common European Law
}

\section{Vers une analyse sistématique de la procédure probatoire en matière d'asile fondé sur l'orientation sexuelle et l'identité de genre dans le droit commun européen}

\author{
Daniel Ángel Borrillo* \\ Víctor Luis Gutiérrez Castillo**
}

\begin{abstract}
SUMARIO: I. Introducción. II. Algunas consideraciones en torno al asilo en Europa. III. La persecución y protección de las personas LGTBI: causa y efecto en el proceso de obtención del estatuto de refugiado. IV. El derecho común europeo de asilo por motivos de orientación sexual e identidad de genero. V. El problema de la inexistencia de la teoría de la prueba en el proceso de asilo y sus posibles soluciones. VI. Aspectos procesales de la presentación de la prueba. VII. La evaluación y valoración de la prueba por las autoridades competentes en materia de asilo. VIII. Criterios para la evaluación de la credibilidad de las declaraciones del solicitante. IX. Conclusión. X. Bibliografía.
\end{abstract}

* Université Paris Nanterre, Francia; ORCID ID: https: //orcid.org/0000-0002-1698-3588.

** Universidad de Jaén, España; ORCID ID: https: / /orcid.org/0000-0002-9329-2836.

Artículo recibido el 2 de enero de 2020 Aprobado para publicación el 9 de octubre de 2020 
RESUMEN: En el presente artículo se analizan los diferentes aspectos jurídicos de la prueba en el proceso de asilo por razón de la orientación sexual y la identidad de género. En concreto, se presta una particular atención al relato o declaración del solicitante tanto en la fase de presentación de la solicitud de asilo como en la evaluación por las autoridades nacionales. El estudio se centrará, principalmente, en el derecho de la Unión Europea y en la jurisprudencia del Tribunal de Justicia de la Unión Europea en la materia.

Palabras clave: asilo, derecho común europeo, Unión Europea, orientación sexual, sistema probatorio.

ABSTRACT: This paper analyzes the different legal aspects of the evidence assessment in asylum claims on the basis of sexual orientation and gender identity. More specifically, it gives special attention to the applicant's account both at the stage of the submission of the asylum application and in the stage of the assessment by the national authorities. This research is focused mainly on the European Union law and the case-law of the Court of Justice of the European Union on this matter.

Key words: asylum, common european law, European Union, sexual orientation, gender identity, evidence assessment.

RÉSUMÉ: Dans cet article, les auteurs analysent les différents aspects de la preuve dans la procédure d'asile pour motif d'orientation sexuelle et d'identité de genre. Plus particulièrement, il s'agit d'étudier le récit de vie du requérant aussi bien lors de sa présentation qu'au moment de son évaluation par les autorités nationales de l'asile. L'étude est focalisée surtout sur le droit de l'Union Européenne et sur la jurisprudence de la Cour de Justice de l'Union Européenne.

Mots-clés: asile, droit commun européen, Union Européenne, orientation sexuelle, identité de genre, preuve. 


\section{INTRODUCCIÓN}

El asilo se inscribe en una vieja y larga tradición occidental. En el mundo antiguo, ante la violencia y los saqueos frecuentes, algunos lugares se beneficiaban de una suerte de inmunidad, como lo demuestra el término mismo de asilo, del griego asulos, "lugar inviolable". De hecho, fue en el templo de Poseidón donde nació tal forma de tutela. El origen religioso explica su naturaleza: el asilo, en tanto espacio sagrado, era una manera de invocar una protección superior. En Roma, dicho lugar era el templo de Asyleus, construido, según la leyenda, por Rómulo en el monte Capitolio.

Desde principios del siglo IV, y con la paulatina cristianización del Imperio romano, la Iglesia apoyó la práctica del asilo, reconocido en los cánones 8, 9 y 10 del Concilio de Sárdica (343-344), siendo posteriormente sancionado por el Imperio con leyes generales a lo largo del siglo V. De esta forma, en su origen este derecho se basó en la sacralidad de determinados espacios con sus implicaciones de inmunidad e inviolabilidad, que se extendían desde el altar a todo el recinto eclesial. Ahora bien, aunque a finales de la Edad Moderna, con la expansión del poder estatal, la institución del asilo fue discutida y entró en desuso, no cabe duda de que esta fórmula de protección contribuiría al perfeccionamiento de las instituciones procesales y judiciales, así como al cambio en la racionalidad y la concepción de los Estados en relación con la inmunidad y la protección de los individuos. En este sentido, las autoridades civiles irían limitando el uso de este privilegio, restringiéndolo a determinados delitos y templos, como demuestra el concordato suscrito entre Felipe V y el papa Clemente XII, en 1737, en el que se distinguía la protección entre templos de asilos e iglesias frías (iglesias rurales y capillas), exceptuadas de la inmunidad local.

Los historiadores coinciden en citar la revocación del Edicto de Nantes, por Luis XIV en 1685, como el hito que marca el comienzo de la tradición europea moderna en materia de asilo territorial. ${ }^{1}$ Sin embargo, no sería sino hasta la Revolución francesa que esta institución adquiriría un carácter laico. En 1789 la Declaración de los Derechos del Hombre y del Ciudadano

1 Grahl-Madsen, Atle, "The European Tradition of Asylum and the Development of Refugee Law”, Journal of Peace Research, Leyden, vol. 3, núm. 3, 1966, pp. 278-289. 
proclama que la resistencia a la opresión forma parte de los derechos "naturales e imprescriptibles del Hombre”. Cuatro años más tarde, la Constitución del 24 de junio de 1793 va más lejos y afirma expresamente que el pueblo francés es el "amigo y aliado natural de los pueblos libres" y "otorga asilo a los extranjeros expulsados de su patria por la causa de la libertad y lo niega a los tiranos". De esta forma, el asilo pasa de ser una práctica religiosa marcada por la caridad a una prerrogativa política del Estado. ${ }^{2}$

Aunque con el movimiento liberal del siglo XIX surge la idea de que el derecho de asilo no está fundado en la soberanía territorial sino en los derechos fundamentales de los individuos, es el siglo XX lo que supone un hito en la evolución del derecho internacional, ya que es el mencionado derecho internacional el que, con cada vez mayor frecuencia, proclama al individuo destinatario directo de sus normas. ${ }^{3}$ De hecho, en el ámbito internacional, el asilo y la protección subsidiaria constituyen un derecho humano fundamental con un reconocimiento universal (la Declaración Universal de los Derechos Humanos, de 1948; el Convenio relativo al estatuto de refugiados, de $1951 ;{ }^{4}$ el Protocolo relativo al estatuto de refugiados, de $1967 ;{ }^{5}$ los Principios de Yogyakarta, de $2007^{6}$ ) y regional (la Convención Americana sobre Derechos Humanos, de $1969 ;{ }^{7}$ la Declaración Americana de los Derechos y Deberes del Hombre, de 1948, o la Carta de Derechos Fundamentales de la Unión Europea ${ }^{8}$ ). Siendo pues, al día de hoy, conforme al texto de la citada Convención de 1951, la base jurídica que permite obtener el estatuto de refugiado en caso de tener "fundados temores de ser perseguido por motivos de raza, religión, nacionalidad, pertenencia a un determinado grupo social u opiniones políticas".

2 Chemin, Anne, "L'asile, un naufrage européen”, Europe Solidaire Sans Frontières, París, octubre de 2015, pp. 1-5.

3 Para más información, Gortázar Rotaeche, Cristina, Derecho de asilo y "no rechazo" del refugiado, Madrid, Dykinson, 1996, pp. 58 y 59.

4 Recueil des Traités des Nations Unies, New York, United Nations Publications, vol. 189, p. 137.

5 Ibidem, vol. 606, p. 267.

6 Los principios de Yogyakarta fueron presentados en Ginebra ante el Consejo de Derechos Humanos de las Naciones Unidas como una carta global el 26 de marzo de 2007.

7 Serie de Tratados de la Organización de Estados Americanos, núm. 36, registro ONU 27/08/1979 núm. 17955.

8 Diario Oficial de la Unión Europea, 26 de octubre de 2012, pp. 391-407. 
Los solicitantes de asilo y refugiados con una orientación sexual o identidad de género diversas, como las personas incluidas en el colectivo LGBTI, se enfrentan a distintas vulnerabilidades. ${ }^{9}$ Además de la grave discriminación y violencia que encuentran en sus países de origen (como exclusión del acceso a los servicios básicos, detención arbitraria), los solicitantes de este colectivo son objeto, con frecuencia, de discriminación y violación de derechos durante los procesos legales y administrativos adoptados por los Estados para determinar su condición de refugiados de conformidad con la legislación nacional e internacional. Siendo Europa uno de los principales destinos de aquellos que escapan o corren riesgo de persecución en sus países de origen sobre la base de su orientación sexual.

Así, entendemos necesario y oportuno hacer un análisis crítico del proceso probatorio en los países europeos. Por lo que se refiere a la hipótesis de nuestro trabajo, partimos de la siguiente presunción: en función de la jurisprudencia del Tribunal de Justicia de la Unión Europea (TJUE) y de los estándares internacionales, es posible establecer elementos procesales que permitan una cierta objetivación del análisis de la prueba en materia de asilo por orientación sexual, garantizando un estándar mínimo de protección de derechos y dignidad de los solicitantes. En nuestro propósito de hacer un análisis crítico del proceso probatorio, a la luz de los estándares internacionales y regionales de protección de derechos humanos, seguiremos un método deductivo, partiendo del derecho de la Unión Europea (UE), la jurisprudencia delTJUE y las recomendaciones del Alto Comisionado de Naciones Unidas para Refugiados (ACNUR) y la Oficina Europea de Apoyo al Asilo (EASO).

\section{Algunas CONSIDERACIONES EN TORNO}

\section{AL ASILO EN EUROPA}

El sistema europeo común de asilo (SECA) determina los estándares mínimos a los que deben ajustarse los países miembros. El artículo 18 de la Car-

9 ACNUR, Directrices sobre Protección Internacional núm. 9: Solicitudes de la condición de refugiado relacionadas con la orientación sexual y/o la identidad de género en el contexto del artículo 1A(2) de la Convención sobre el Estatuto de los Refugiados de 1951 y/o su Protocolo de 1967, Ginebra, ACNUR, enero de 2012. 
ta de los Derechos Fundamentales de la UE reconoce y garantiza el derecho de asilo dentro del respeto de las normas de la Convención de Ginebra del 28 de julio de 1951 y del Protocolo del 31 de enero de 1967 sobre el Estatuto de los Refugiados, de conformidad con el Tratado constitutivo de la Comunidad Europea. Asimismo, el artículo 19 completa el dispositivo, al disponer que "nadie podrá ser devuelto, expulsado o extraditado a un Estado en el que corra un grave riesgo de ser sometido a la pena de muerte, a tortura o a otras penas o tratos inhumanos o degradantes".

En este orden de ideas, también es oportuno mencionar, en el ámbito de la UE, la existencia del Manual sobre Asilo, que funciona a modo de guía para que las autoridades nacionales de los distintos Estados miembros operen de manera similar al momento de recibir una solicitud de asilo de acuerdo con las normas internacionales vigentes en la materia. ${ }^{10}$ El apartado 3.1.1. de dicho manual trata de la "naturaleza del riesgo". Recuerda, en primer lugar, que el artículo 9o. de la directiva 95/2011 ${ }^{11}$ también especifica que la persecución puede adoptar diversas formas, como actos de violencia (física o psíquica) o incluso medidas administrativas o jurídicas (entre las que pueden encontrarse leyes que prohíben la homosexualidad). Las diversas formas de persecución y los actos mencionados previamente deben poder atribuirse a una de las cinco categorías de persecución derivadas de la Convención de Ginebra de 1951, a saber: raza, nacionalidad, religión, pertenencia a un determinado grupo social y opinión política. Cinco categorías consagradas en el artículo 10 de la citada directiva ${ }^{12}$ que, en su versión modificada, exige explícitamente la debida consideración de la orientación sexual a los efectos de determinar la pertenencia a un determinado grupo social. ${ }^{13}$

10 Agencia de los Derechos Fundamentales de la Unión Europea, Manual de derecho europeo sobre asilo, fronteras e inmigración, Luxemburgo, Oficina de Publicaciones de la Unión Europea, 2014.

11 Directiva 2011/95/UE del Parlamento Europeo y del Consejo del 13 de diciembre de 2011, Diario Oficial de la Unión Europea, 20 de diciembre 2011, pp. 9-26.

12 Idem.

13 Por lo que respecta a la diferencia entre orientación sexual e identidad de género, cabe señalar que está establecida en los Principios de Yogyakarta. Se entiende por orientación sexual la capacidad de cada persona de sentir una profunda atracción emocional, afectiva y sexual por personas de un sexo diferente o de un mismo sexo o de más de un sexo, así como a la capacidad de tener relaciones íntimas y sexuales con estas personas. Se entiende por identidad de género la profundamente sentida experiencia interna e individual del gé- 
Por lo que respecta al Convenio Europeo de Derechos Humanos (CEDH), cabe señalar que, aunque no hace referencia expresa al asilo, permite de alguna manera efectivizarlo a partir de una interpretación amplia de su artículo 3o., en el que se establece que "nadie podrá ser sometido a tortura ni pena o tratos inhumanos o degradantes". Y es que, según los jueces de Estrasburgo, constituye una violación a dicho artículo la expulsión a un país donde la persona corre el riesgo de padecer tales tratos. El procedimiento de asilo constituye, de ese modo, un mecanismo del que disponen los Estados para evitar una condena por parte del Tribunal Europeo de Derechos Humanos (TEDH) por violación del artículo 3o. del CEDH.

Jurídicamente, podríamos definir el asilo como el derecho a beneficiarse de la posibilidad de entrar y permanecer en el país de acogida a efectos de encontrar una protección y de evitar así los riesgos de persecuciones en el país de origen. El derecho de asilo es otorgado a las personas a las que el Estado de acogida reconoce el estatuto de refugiado. Ahora bien, durante mucho tiempo ese derecho ha sido denegado a las personas homosexuales y transexuales. $Y$ es que la definición de refugiado del derecho internacional es sexualmente neutra y, por ende, no se reconoce de manera expresa la protección en función de género, orientación sexual o identidad de género de las personas. En este contexto, un individuo homosexual o transgénero no podría aspirar a obtener el estatuto de refugiado por la simple consideración de su orientación o identidad sexual.

Teniendo en cuenta lo expuesto, la única posibilidad de obtener el asilo es fundar su pretensión en la categoría de "pertenencia a un determinado grupo social” del artículo 1o. del Convenio de Ginebra. Gracias a la jurisprudencia de algunos países miembros de la UE, en un primer momento, dicha categoría ha permitido reconocer como refugiados a los individuos perseguidos en razón de su sexualidad. Este ha sido el caso, por ejemplo, de la justicia francesa, que en 1998 admitió que la situación de las personas transexuales en Argelia permitía “considerarlas como un grupo cuyos miembros son por razón de sus características comunes expuestos a persecución

nero de cada persona, que podría corresponder o no con el sexo asignado al momento del nacimiento, incluyendo el sentido personal del cuerpo (que, de tener la libertad para escogerlo, podría involucrar la modificación de la apariencia o la función corporal a través de medios médicos, quirúrgicos o de otra índole) y otras expresiones de género, incluyendo el vestido, el modo de hablar y los amaneramientos. 
por las autoridades y la sociedad argelina”, ${ }^{14}$ posición que mantendría en relación con la comunidad homosexual rusa en el 2005. Planteamiento que también sería seguido por la justicia española, la cual reconoció la posibilidad de que la persecución por orientación sexual e identidad de género pudiera dar lugar a la obtención de protección internacional, incluso antes de que lo hiciera expresamente la actual Ley 12/2009 en sus artículos 3o. y 7o. Buena prueba de ello son las sentencias del 16 de septiembre de 2006 y del 28 de noviembre de 2008 del Tribunal Supremo, las cuales reconocieron que una persecución llevada a cabo por las autoridades gubernamentales contra una persona por razón de su orientación sexual puede encontrar amparo en la Convención de Ginebra de 1951 y en la, entonces vigente, Ley de Asilo 5/84, del 26 de octubre. ${ }^{15}$

El derecho europeo reconocería más tarde la orientación sexual como parte de la categoría "pertenencia a un determinado grupo social", como también lo harían los Estados miembros integrando dicha protección por sus respectivas legislaciones nacionales, como ha hecho España en la Ley 12/2009 reguladora del derecho de asilo y de la protección subsidiaria, ${ }^{16}$ donde se establece que "la condición de refugiado se reconoce a toda persona que, debido a fundados temores de ser perseguida por motivos de raza, religión, nacionalidad, opiniones políticas, pertenencia a determinado grupo social, de genero u orientación sexual...”.

14 Original en francés, la traducción es nuestra, CRR (Commission des Recours des Réfugiés) décision "Ourbih" de 15 de mayo de 1998. Para profundizar sobre este tema, Romboli, Roberto, "La homosexualidad como elemento de discriminación: principios constitucionales y jurisprudencia de los jueces constitucionales y de las Cortes europeas”, en Cuesta López, Víctor y Santana Vega, Dulce M. (coords.), Estado de derecho y discriminación por razón de género, orientación e identidad sexual, Las Palmas de Gran Canaria, Servicio de Publicaciones y Difusión Científica de la ULPGC-Aranzadi, 2014, p. 298; Créac'h, Xavier, "Les évolutions dans l'interprétation du terme réfugié”, Revue Hommes et Migrations, París, núm. 1238, julio-agosto de 2002, pp. 65-74.

15 Díaz Lafuente, J., "El derecho de asilo por motivos de orientación sexual e identidad de género”, Revista de Derecho Político, Madrid, núm. 89, enero-abril de 2014, pp. 364 y 365. Para más información, Santolaya Machetti, Pablo y Pérez-Moneo, Miguel Agapito, El derecho de asilo en la jurisprudencia (julio 2005-junio 2006), Barcelona, CIBOD, 2006. Esta línea jurisprudencial ha sido mantenida (y reforzada) tras la publicación de la Ley 12/2009, dando lugar a sentencias que han constituido un hito en la protección de la comunidad LGTBI en materia de asilo.

16 BOE, núm. 263, 31 de octubre de 2009, pp. 4-28. 
Por otra parte, cabe señalar que la orientación sexual como riesgo de persecución trae aparejada la dificultad de comprobar la credibilidad de dicha sexualidad. Probar de forma objetiva la orientación sexual es particularmente complicado, pues el solicitante a menudo no puede presentar elementos que le permitan atestar tal situación, como documentos personales, fotografías, testimonios, artículos de prensa, certificados médicos, etcétera. La cuestión se complica aún más cuando el solicitante lleva una doble vida e, inclusive, se ve obligado a contraer matrimonio con una persona de sexo opuesto en su país. Ante la dificultad de presentar pruebas objetivas, la solidez del dossier de asilo dependerá de las declaraciones del solicitante, las cuales devienen en el elemento central del procedimiento.

\section{LA PERSECUCIÓN Y PROTECCIÓN DE LAS PERSONAS LGTBI:}

CAUSA Y EFECTO EN EL PROCESO DE OBTENCIÓN

DEL ESTATUTO DE REFUGIADO

\section{La causa: el temor fundado}

El primer elemento que desencadena el proceso de asilo es el temor fundado de persecución que corren algunas personas en razón de su orientación sexual o de su identidad de género. Se trata de un sentimiento subjetivo que debe apoyarse en una situación objetiva documentada por varios actores: organizaciones no gubernamentales, organismos de derechos humanos, agencias de Estado, autoridades consulares, testimonios periodísticos, etcétera. Al día de hoy, 73 países penalizan las relaciones sexuales entre personas del mismo sexo y nueve de ellos lo hacen con la pena capital, como es el caso de Mauritania, Nigeria, Sudan, Yemen, Irán, Afganistán, Pakistán, Arabia Saudí y Somalia. El auge de los integrismos religiosos en el mundo augura una situación aun más desalentadora. Las sectas evangélicas en el poder en varios países de América Latina, la influencia de la Iglesia ortodoxa en Rusia, la expansión del islamismo radical y la del fundamentalismo judío ensombrecen la situación de las personas LGBTI, haciéndolas objeto de violencia y discriminación.

Además de los Estados que criminalizan la homosexualidad, existen otros donde la violación “correctiva” de lesbianas, las terapias de conversión 
o reorientación sexual para "curar" la homosexualidad, los matrimonios forzados, el internamiento psiquiátrico, el acoso y la discriminación son moneda corriente sin que las autoridades intervengan para proteger a las posibles víctimas. En la mayoría de los países de origen, el Estado no tiene el monopolio de la persecución, e inclusive allí donde no hay penalización, la familia, los vecinos, los empleadores y hasta la policía pueden ser fuente de violencia contra las personas LGBTI.

En los Estados en los que se sanciona penalmente la homosexualidad dicho concepto se encuentra ausente del orden jurídico represivo. Mientras que en Occidente se utilizan términos que se refieren a una identidad (orientación sexual, identidad de género, LGBTI...), en los países de origen la terminología hace referencia a un acto "contra natura", como "sodomía", "atentado a las buenas costumbres", "indecencia grave", "relaciones carnales antinaturales", etcétera. Según Amnistía Internacional, en los últimos años la situación se ha degradado particularmente en África subsahariana, donde 38 países siguen considerando la homosexualidad como una infracción penal. ${ }^{17}$ En 2016 el Consejo de Derechos Humanos de las Naciones Unidas ha adoptado una resolución mediante la cual se nombra un experto independiente sobre la protección contra la violencia y la discriminación basadas en la orientación sexual o la identidad de género para que informe a la Organización de las Naciones Unidas (ONU) acerca de las causas de la violencia homofóbica y los medios para combatirla. Según este informe

Las relaciones consentidas entre personas del mismo sexo siguen siendo delito en 73 países, lo que expone a las personas al riesgo de detenciones, chantajes y extorsiones y fomenta la estigmatización, la discriminación y la violencia. Si bien cinco Estados han despenalizado la homosexualidad desde 2011, en otros se han aprobado o propuesto leyes discriminatorias, se han ampliado las sanciones y se han establecido restricciones discriminatorias a la libertad de expresión y de asociación. ${ }^{18}$

La dimensión geopolítica es inherente al derecho de asilo. Las autoridades nacionales fundan sus decisiones sobre la base de un análisis respecto de

17 Amnesty International, Mapping Anti-Gay Laws in Africa, Londres, Amnesty International UK, 31 de mayo de 2018.

18 Consejo de Derechos Humanos, Informe del experto independiente sobre la protección contra la violencia y la discriminación por motivos de orientación sexual o identidad de género, Naciones Unidas, 19 de abril de 2017. 
la situación en los países de origen del solicitante. En ese sentido, la directiva 2011/95/UE ${ }^{19}$ establece, en su artículo 4o., inciso 3, que

La evaluación de una solicitud de protección internacional se efectuará de manera individual e implicará que se tengan en cuenta: a) todos los hechos pertinentes relativos al país de origen en el momento de resolver sobre la solicitud, incluidas las disposiciones legales y reglamentarias pertinentes del país de origen y el modo en que se aplican.

El dispositivo se completa con el artículo 10, inciso $3 \mathrm{~b}$ ), de la directiva 2013/32/UE, ${ }^{20}$ según el cual "los Estados miembros garantizarán que las resoluciones sobre las solicitudes de protección internacional de la autoridad decisoria se dicten tras un examen adecuado". A tal fin, los Estados miembros garantizarán que se obtenga información precisa y actualizada de diversas fuentes, por ejemplo, información de la EASO, ${ }^{21}$ del Alto Comisionado de las Naciones Unidas para los Refugiados (ACNUR) y de organizaciones internacionales de defensa de los derechos humanos, respecto de la situación general imperante en los países de origen de los solicitantes.

\section{El efecto: la protección de las personas LGBTI}

Como señalamos anteriormente, el artículo 1o. de la Convención de Ginebra establece que debe ser considerado como refugiado toda persona que

... debido a fundados temores de ser perseguida por motivos de raza, religión, nacionalidad, pertenencia a determinado grupo social u opiniones políticas, se encuentre fuera del país de su nacionalidad y no pueda o, a causa de dichos temores,

19 Directiva 2011/95/UE del Parlamento Europeo y del Consejo, 13 de diciembre de 2011, Diario Oficial de la Unión Europea, 20 de diciembre de 2011, pp. 9-26.

20 Directiva 2013/32/UE del Parlamento Europeo y del Consejo, 26 de junio de 2013, Diario Oficial de la Unión Europea, 29 de junio de 2013, pp. 60-95.

21 La Oficina Europea de Apoyo al Asilo es una agencia creada por el Reglamento 439/2010 de la Unión Europea para aumentar la cooperación de los Estados miembros de la UE en materia de asilo, mejorar la implementación del Sistema Europeo Común de Asilo y apoyar a los Estados miembros bajo presión, Diario Oficial de la Unión Europea, 29 de mayo de 2010, pp. 11-28. 
no quiera acogerse a la protección de tal país; o que, careciendo de nacionalidad y hallándose, a consecuencia de tales acontecimientos, fuera del país donde antes tuviera su residencia habitual, no pueda o, a causa de dichos temores, no quiera regresar a él. ${ }^{22}$

Holanda fue el primer país en reconocer la orientación sexual como motivo de persecución en una decisión del Consejo de Estado el 13 de agosto de 1981. Del mismo modo, en 2002 el ACNUR publicó una nota en la que afirmaba que la persecución motivada por la orientación sexual debe ser considerada relevante para la solicitud de asilo. ${ }^{23}$

La categoría “orientación sexual", interpretada como pertenencia a un determinado grupo social de la Convención de Ginebra, aparece por primera vez en el ámbito de la UE de manera explícita en la directiva 2004/83/ CE del 29 de abril de 2004, ${ }^{24}$ en su artículo 10 d), cuando establece que

...se considerará que un grupo constituye un determinado grupo social si, en particular: los miembros de dicho grupo comparten una característica innata o unos antecedentes comunes que no pueden cambiarse, o bien comparten una característica o creencia que resulta fundamental para su identidad o conciencia que no se les puede exigir que renuncien a ella y dicho grupo pose una identidad diferenciada en el país de que se trate por ser percibido como diferente por la sociedad que lo rodea. En función de las circunstancias imperantes en el país de origen, podría incluirse en el concepto de grupo social determinado un grupo basado en una característica común de orientación sexual...

La directiva 2011/95/UE del 13 de diciembre de 2011, que modifica la directiva de 2004 y refunde las normas relativas a los requisitos para el derecho de asilo, retoma la categoría de "orientación sexual" de ésta ultima y añade la expresión "los aspectos relacionados con el sexo de la persona”, que permite proteger también la identidad de género.

22 Recueil des Traités des Nations Unies, cit., vol. 189, p. 137.

23 ACNUR, Directrices sobre protección internacional. La persecución por motivos de género en el contexto del artículo 1A (2) de la Convención de 1951 sobre el Estatuto de los Refugiados y/o su Protocolo de 1967 (HCR/GIP/02/0), Ginebra, ACNUR, 7 de mayo de 2002.

24 Directiva 2004/83/CE del Consejo, 29 de abril de 2004, Diario Oficial de la Unión Europea, 30 de septiembre de 2004, pp. 12-23. 


\title{
IV. EL DERECHO COMÚN EUROPEO DE ASILO
}

POR MOTIVOS DE ORIENTACIÓN SEXUAL

\author{
E IDENTIDAD DE GENERO
}

Para determinar si el solicitante puede acceder al estatuto de refugiado, las autoridades del asilo en Europa deberán determinar si en su país de origen los homosexuales constituyen un grupo social en el sentido de la directiva 2011/95/UE. En el asunto F. c. Bevándorlási és Allampolgarsagi Hivatal, el Tribunal de Justicia de la Unión Europea (TJUE), ante una cuestión prejudicial planteada por las autoridades judiciales húngaras en $2016,{ }^{25}$ recuerda que el solicitante puede beneficiarse de la protección internacional en la medida en que pertenece a un grupo social perseguido. ${ }^{26}$ Dicha protección debe, asimismo, aplicarse si el solicitante fuera únicamente percibido por los autores de la persecución como miembro de dicho grupo social. Lo que importa, en consecuencia, no es tanto la orientación sexual del solicitante, sino la manera en que es visto por quien lo discrimina. En teoría, las autoridades competentes en materia de asilo deberían proceder a un examen sociológico objetivo respecto de la situación general de los homosexuales en el país del solicitante, y no a un análisis psicológico acerca de la sexualidad de este último. Lo que, sin embargo, no es siempre el caso en la práctica.

El TJUE ha considerado, también, que si existe una legislación que penaliza los comportamientos homosexuales, los solicitantes de dicho país deben ser, en principio, considerados pertenecientes a un determinado grupo social. No obstante, la penalización en cuanto a tal no constituye una

25 ElTribunal de lo Contencioso-Administrativo y de lo Social de Szeged, en Hungría (Szegedi Közigazgatási és Munkaügyi Bíróság), interpuso por resolución del 8 de agosto de 2016 una cuestión prejudicial al TJUE, planteando dos cuestiones: por una parte, si la aplicación del artículo 4o. de la directiva 2004/83/EC permite, a la luz de la Carta de los Derechos Fundamentales de la UE, el uso de dictámenes de expertos basados en test de personalidad para la concesión de asilo a solicitudes planteadas por personas LGBTI y, por otra, si debería ser impedido su uso a las autoridades húngaras para la determinación de la veracidad de los relatos de dichos solicitantes.

26 Sentencia del TJUE (Sala Tercera), 25 de enero de 2018, asunto C-473/16, ECLI:EU:C:2018:36. 
persecución susceptible de otorgar el derecho de asilo, salvo que la pena sea la prisión efectivamente aplicada ${ }^{27}$ Del mismo modo, elTJUE recuerda en esta sentencia que la persecución invocada debe tener un cierto nivel de gravedad y que cualquier violación de los derechos fundamentales del solicitante no significa un riesgo de persecución en el sentido utilizado por la Convención de Ginebra. El juez de Luxemburgo invita, de este modo, a las autoridades nacionales a analizar las informaciones respecto del país de origen; es decir, no sólo lo que dicen las leyes represivas, sino también su grado de aplicación.

Respecto de la práctica de discreción solicitada por algunas autoridades nacionales, el TJUE pone fin a tal condición indicando que "A la hora de examinar una solicitud destinada a obtener el estatuto de refugiado, las autoridades competentes no pueden razonablemente esperar que, para evitar el riesgo de persecución, el solicitante de asilo oculte su homosexualidad en su país de origen o actúe con discreción al vivir su orientación sexual". ${ }^{28}$ De hecho, exigir a los miembros de un determinado grupo social que comparten la misma orientación sexual que la disimulen, sería contrario al reconocimiento mismo de tal grupo social.

\section{EL PROBLEMA DE LA INEXISTENCIA DE LA TEORÍA \\ DE LA PRUEBA EN EL PROCESO DE ASILO \\ Y SUS POSIBLES SOLUCIONES}

Como es sabido, el derecho europeo no dispone de una teoría de la prueba en materia de asilo. La citada directiva de 2011 se refiere únicamente a la "valoración de hechos y circunstancias", así como a los elementos necesarios para fundamentar la solicitud de asilo. Estos elementos son definidos por su artículo 4o., inciso 2, cuando reza: "las declaraciones del solicitante y toda la documentación de la que disponga”.

27 En este sentido se pronunció el TJUE ante una cuestión prejudicial promovida por Países Bajos. Sentencia del TJUE (Sala Cuarta), X.Y. y Z. c. Minister voor Immigratie en Asiel, 7 de noviembre 2013, asuntos acumulados C-199/12, C-200/12 y C 201/12, ECLI:EU:C: 2013:720.

28 Sentencia del TJUE (Sala Cuarta), X.Y.y Z. c. Minister voor Immigratie en Asiel, cit. 
En sentido amplio, la prueba es el modo de demostrar un hecho. Del punto de vista jurídico, contrariamente a la prueba científica, el objetivo no es tanto acceder a la verdad material de los hechos, sino, más bien, convencer al juez de su veracidad. Lévy-Bruhl afirma que "en materia judicial, la prueba tiene esencialmente como finalidad persuadir al juez. No es tanto la búsqueda de la verdad para lo que sirve la prueba sino el medio de crear una convicción en la mente del juez" ${ }^{29}$ Ante todo, se trata de una actividad intelectual, un razonamiento tendente a una demostración susceptible de convencer al juez no tanto de la verdad, sino de la verosimilitud de los hechos invocados por el solicitante. Podemos coincidir, entonces, con Lévy-Bruhl, cuando define la prueba como "un mecanismo destinado a establecer una convicción respecto de un hecho incierto”. Según el adagio latino idem est non esse et non probari, lo que no se puede probar no es jurídicamente relevante. Contrariamente al derecho civil o penal, no existe en el derecho administrativo continental una teoría de la prueba. Es la jurisprudencia la que ha creado algunas reglas que permiten organizar el principio general de la libertad de la prueba propio al derecho administrativo. Las autoridades competentes en materia de asilo se encuentran así con la responsabilidad de conducir el proceso y utilizar dentro del procedimiento inquisitorio los poderes generales de instrucción e investigación.

En los procedimientos en materia de asilo es frecuente encontrarse con muy pocas pruebas materiales susceptibles de fundar la pretensión del solicitante. Dicha situación hace muy complicada la instrucción y sumerge a las autoridades del asilo en una incertidumbre generalizada. A ello se suma que las declaraciones de los solicitantes se refieren a contextos culturales y geopolíticos lejanos a los cuales la instrucción tiene acceso únicamente a través de la documentación de organismos de derechos humanos u organizaciones no gubernamentales (ONGs). La instrucción y la evaluación tanto de los hechos como de las declaraciones del solicitante se realiza a partir de hipótesis de una probabilidad aproximativa. Si bien es cierto que la prueba hace intervenir disposiciones psicológicas tanto de quien la presenta como de quien la evalúa, los elementos objetivos no pueden ser descuidados. En este sentido, en función de la teoría general de la prueba, los mismos pueden analizarse en respuesta a cuatro pregun-

29 Lévy-Bruhl, Henri, “Réflexions sur la preuve judiciaire”, Journal de Psychologie Normale et Pathologique, París, vol. XLV, 1951, p. 82. 
tas principales: ¿qué se debe probar?, ¿cómo se debe probar?, ¿quien debe probar?, y ¿cuándo se debe probar?

\section{ASPECTOS PROCESALES DE LA PRESENTACIÓN DE LA PRUEBA}

El objeto de la prueba consiste en dar respuesta a la siguiente pregunta: ¿qué debe probar el solicitante para obtener el estatuto de refugiado en un proceso de asilo? Según el derecho común europeo, el solicitante del derecho de asilo, en cualquiera de los países miembros, debe probar tres elementos: 1) el hecho generador, es decir, el riesgo personal de persecución que corre en su país de origen; 2) la pertenencia a un determinado grupo social como categoría de protección del derecho internacional recepcionada en el derecho europeo, y 3) el nexo de causalidad entre el hecho generador y la categoría en cuestión.

\section{El objeto: ¿qué se debe probar?}

La respuesta a esta pregunta constituye el objeto de la prueba, la cual reviste tres condiciones en materia de asilo: el hecho generador de la persecución, la pertenencia a un determinado grupo como garantía de protección y la existencia de una relación de causalidad entre el hecho generador y la categoría en cuestión.

Por lo que se refiere al elemento sustancial o hecho generador, cabe señalar que éste viene determinado por los actos y los motivos de persecución a los que hace referencia el artículo 1o. de la Convención de Ginebra. Elementos esos que deben ser analizados a la luz de lo que establecen los artículos 9o. y 10 de la directiva 2011/95/UE; es decir, que se trate de actos "suficientemente graves por su naturaleza o carácter reiterado como para constituir una violación grave de los derechos humanos fundamentales", debiendo, en particular, revestir las siguientes formas: actos de violencia física o psíquica, incluidos los actos de violencia sexual; medidas legislativas, administrativas, policiales o judiciales discriminatorias; penas desproporcionadas; denegación de tutela judicial... 
El temor de persecución, y no la persecución efectiva, es lo que se debe probar como hecho generador. La persecución que se teme debe revestir una cierta gravedad, como hemos visto, y referirse, además, personalmente al solicitante. El temor subjetivo debe así fundarse en una situación de riesgo objetivo para que sea considerado razonable. Como lo recuerda el ACNUR, las notas preparatorias de la redacción de la Convención ayudan a esclarecer este tema. Una de las categorías de refugiados a la que hace referencia el Anexo I de la Constitución de la Organización Internacional de los Refugiados (OIR), es la de personas "que expresaron objeciones validas a retornar" a sus países, definiéndose "objeción valida" como "persecución, o temor, basado en motivos razonables de persecución”. El Manual de la OIR enunciaba que la expresión "motivos razonables" debía de entenderse en el sentido de que el solicitante había ofrecido "un relato creíble y coherente de las causas por las cuales teme la persecución". ${ }^{30}$

Cabe recordar, asimismo, que el TEDH prohíbe la expulsión cuando el solicitante se encuentra expuesto al retornar a su país de origen a un riesgo de muerte o tortura o penas y tratamientos inhumanos y degradantes. Los hechos relevantes presentados por el solicitante son confrontados a las fuentes objetivas de información disponibles como los informes de Naciones Unidas, el Consejo de Europa, la EASO, la Agencia de los Derechos Fundamentales de la Unión Europea (FRA), los informes de las ONG (Amnesty International, ILGA, Human Right Watch), los informes de organismos nacionales (Refugee Documentation Centre de Irlanda, la agencia sueca de inmigración, el defensor del pueblo, la comisión canadiense de inmigración, etcétera), las publicaciones académicas, los documentos jurídicos (leyes, sentencias...), los artículos de prensa y también las fuentes provenientes de redes sociales, así como de las visitas in loco y misiones de oficinas de asilo en los países de origen.

La pertenencia a un determinado grupo social como categoría de protección del derecho internacional recepcionada en el derecho europeo es el segundo elemento que debe probarse. Las diferentes formas de persecución deben imputarse a algunos de los cinco motivos establecidos en la Convención de Ginebra (raza, religión, nacionalidad, pertenencia a un determinado grupo social u opiniones políticas). Como lo hemos analizado anteriormente,

30 ACNUR, Nota sobre la carga y el mérito de la prueba en las solicitudes de asilo, Ginebra, ACNUR, 16 de diciembre de 1998, p. 3. 
la orientación sexual y la identidad de género entran en la categoría "pertenencia a un determinado grupo social". Tal categoría no significa que existan estructuras colectivas, insistimos, basta con que el solicitante sea percibido y reconocido por la sociedad de origen como miembro de un grupo especifico. Es la sociedad hostil a la homosexualidad la que hace del solicitante un miembro de un determinado grupo social y no su identidad (teoría de la mirada social). Es el juez, por consiguiente, el que debe analizar de manera individual el caso concreto. Y es que, no debemos olvidar, que el temor a la persecución puede provenir del aparato represivo del Estado, de actores no estatales o de la hostilidad de la propia familia del solicitante.

Según el ACNUR, "identificarse a sí mismo como LGBT debe tomarse como una indicación de la orientación sexual de la persona" ${ }^{\text {11 }}$ (teoría de la autoidentificación). En la mayoría de los casos, los agentes del asilo preguntan al solicitante cuál es su orientación sexual y aunque es la teoría de la mirada social la que debería prevalecer, en realidad es muy difícil obtener el asilo sin declarase a sí mismo como homosexual. Por último, para que los hechos invocados por el solicitante puedan ser establecidos en la instrucción, es necesario probar el nexo de causalidad entre el riesgo de persecución y la pertenencia a un determinado grupo social (orientación sexual o identidad de género). La prueba de dicho nexo de causalidad puede realizarse por cualquier medio (prueba documental, testimonio...).

\section{Aspectos jurídicos relevantes del sistema de libertad de prueba}

En la teoría general de la prueba encontramos dos grandes sistemas: la prueba legal y la libertad de la prueba. En el primero, propio del derecho civil y penal, se determina por ley tanto las pruebas admitidas como su jerarquía (preuve légale), mientras que el segundo, propio del derecho administrativo, deja la apreciación de la prueba en manos del juez (liberté de preuve). El asilo se rige por el régimen de la libertad de la prueba. En principio, cualquier prueba fiable resulta admisible. El juez evalúa con toda libertad

31 ACNUR, Nota de orientación sobre las solicitudes de la condición de refugiado relacionadas con la orientación sexual y la identidad de género, trad. de la Unidad Legal Regional del Bureau de las Américas, Ginebra, ACNUR, noviembre de 2008, p. 20. 
el valor de los elementos de prueba que el solicitante le somete y toma su decisión en función de la íntima convicción. El criterio que determina la íntima convicción, como lo indicamos anteriormente, no es la verdad, sino la verosimilitud.

Por lo que se refiere a la carga de la prueba (¿quién debe probar?), cabe señalar que el principio actori incumbit probatio tiene que interpretarse de manera flexible por la naturaleza misma de todo proceso administrativo en el cual las partes se encuentran en situación de desigualdad. En efecto, no se le exige tanto al solicitante que aporte la prueba completa, sino ciertos indicios que sirvan como comienzo de prueba. Inclusive el derecho europeo no utiliza el término prueba para referirse a los procedimientos de asilo. El artículo 4o. de la directiva de 2011 establece únicamente que "es obligación del solicitante presentar lo antes posible todos los elementos necesarios para fundamentar su solicitud". Según el ACNUR, "esta obligación se cumple por parte del solicitante presentando un informe veraz de los hechos que fundamentan la solicitud, de modo que, basándose en los hechos, se pueda llegar a tomar una decisión adecuada”. ${ }^{32}$ En realidad, la directiva no impone la carga de la prueba al solicitante, sólo contempla que los Estados miembros puedan considerar la obligación de éste de dar argumentos que permitan cimentar sus alegaciones. La noción "fundamentar su solicitud" implica, efectivamente, un deber menos pesado que aquel clásico de "carga de la prueba".

Otras de las cuestiones importantes en relación con el sistema probatorio, es la problemática de los plazos. Según la directiva 2011/95, el solicitante debe presentar con la mayor rapidez posible su solicitud, a menos que pueda demostrar la existencia de razones fundadas para no haberla presentado a tiempo (artículo 4o., inciso d). Según el ACNUR, en la practica el término "lo antes posible" se define por el plazo y las modalidades del procedimiento. Asimismo, en cuanto a presentación de declaraciones, pruebas documentales y de otro tipo, el ACNUR insta a las autoridades decisorias a que velen por que el procedimiento permita, y las orientaciones normativas instruyan, a los responsables de la decisión a tener en cuenta las circunstancias personales y contextuales de los solicitantes, incluyendo los medios a su disposición para obtener pruebas documentales y de otro tipo, traducciones, cuando sean necesarias.

32 ACNUR, Nota sobre la carga y el mérito..., cit., p. 2. 
Es probable que el solicitante no declare de inmediato su homosexualidad a las autoridades competentes en materia de asilo, en tal caso, el TJUE ha establecido que no se puede desestimar una solicitud por el mero hecho de que el solicitante "no reveló su orientación sexual en la primera ocasión que se le ofreció de exponer los motivos de persecución". ${ }^{33}$ Como subraya Tissier-Raffin, el TJUE confirma una visión no estereotipada de la orientación sexual, pues se apoya en la idea de que la revelación de elementos íntimos de la identidad puede verse afectada por sentimientos profundos de vergüenza u homofobia interiorizada, traumas, etcétera, lo cual explica la demora del solicitante en desvelar su condición. ${ }^{34}$

\section{LA EVALUACIÓN Y VALORACIÓN \\ DE LA PRUEBA POR LAS AUTORIDADES COMPETENTES}

EN MATERIA DE ASILO

\section{La instrucción}

El principio de libertad de prueba que gobierna el proceso en materia de asilo no significa que no existan reglas que determinen la validez de los medios probatorios. De hecho, como reconoce el ACNUR en su documento sobre protección de las personas con orientación sexual e identidad de género diversas, ${ }^{35}$ es importante garantizar que los solicitantes de asilo LGBTI gocen de acceso a una evaluación justa y eficiente de sus solicitudes de la condición de refugiado y que su dignidad se mantenga durante todo el procedimiento de determinación de la condición de refugiado. En este sentido, el artículo 10, inciso 3 a) de la directiva 2013, establece un principio general según el cual "el examen de las solicitudes y la adopción de las resoluciones se efectúen de forma individual, objetiva e imparcial”,

33 Sentencia del TJUE (Gran Sala), A y otros c. Staatssecretaris van Veiligheid en Justitie, 2 de diciembre de 2014, asuntos acumulados C-148/13 a C-150/13, ECLI:EU:C:2014:2406.

34 Tissier-Raffin, Marion, "L'orientation sexuelle comme motif de persécution doit être appréciée dans la dignité”, La Revue des Droits de L’homme, París, núm. 28, enero de 2015.

35 ACNUR, Protección de las personas con orientación sexual e identidad de género diversas. Informe mundial sobre los esfuerzos del ACNUR para proteger a solicitantes de asilo y refugiados lesbianas, gais, bisexuales, transgénero e intersex, Ginebra, ACNUR, diciembre de 2015. 
que, obviamente, también debe ser aplicable a este colectivo. Es por esta razón por lo que elTJUE, en tanto que intérprete del derecho europeo, ha establecido un régimen probatorio en el que ciertas pruebas se encuentran prohibidas, en particular aquellas que atentan a la vida privada y la dignidad del solicitante.

En este sentido, el principio de cooperación con el solicitante es, según el artículo 4o. de la directiva de 2011, un deber del organismo de evaluación de la prueba. Pudiendo el solicitante desconocer la obligación de fundar sus alegaciones, y más aun cómo hacerlo, es la administración que instruye a la que le incumbe la tarea de asistir al solicitante por todos los medios de que disponga, como lo indica el TJUE al establecer que "el Estado debe cooperar con el solicitante en el momento de la determinación de su alegación". ${ }^{36}$ En caso de imposibilidad de aportar pruebas materiales (documentos, testimonios...), sus declaraciones son suficientes siempre y cuando las mismas se consideren coherentes y verosímiles y no contradigan la información específica de carácter general disponible. La credibilidad general del solicitante constituye el elemento principal de evaluación. El TJUE considera que la identificación como LGBTI no puede ser el único criterio que permita evaluar la solicitud de asilo. Y la declaración del solicitante constituye, pues, el punto de partida para el examen de tal solicitud.

\section{Las pruebas admitidas en las solicitudes} de asilo de personas $L G T B I$

En principio, todos los medios de pruebas son admisibles con la única restricción, como veremos más tarde, del respeto a la vida privada y a la dignidad humana del solicitante. Este último presentará, con la mayor rapidez posible, todos los elementos útiles que sirvan para fundar su solicitud: la declaración individual y el relato de vida detallado que permita justificarla, su historia y la de su familia y cualquier documento o testimonio que fundamente su situación. En la práctica, las principales pruebas admitidas, además de las declaraciones (relato de vida), son aquellas que permiten establecer episodios violentos que el solicitante ha padecido, como por

36 Sentencia del TJUE (Gran Sala), A, B et C c. Staatssecretaris van Veiligheid en Justitie..., cit. 
ejemplo, un certificado médico expedido en el país de acogida en el que se confirmen las secuelas de tales episodios, tanto físicas como psicológicas.

La prueba testimonial resulta de las declaraciones de personas que relatan lo que han visto u oído. Aunque muchas veces es difícil aportar tales pruebas en los procesos de asilo por orientación sexual, los testimonios pueden arrojar luz sobre elementos importantes del proceso. En muchos casos, el solicitante presenta el testimonio de una asociación LGBTI del país de acogida, en el que los miembros de la ONG certifican que éste ha pedido ayuda y/o ha participado en las actividades de la asociación. Pruebas éstas que deberían ser aceptadas. Y es que, indica el ACNUR en su Manual de Procedimientos y Criterios para Determinar la Condición de Refugiado..., el requisito de la prueba de los solicitantes en estas condiciones no debería aplicarse estrictamente en vista de las dificultades que encuentran los solicitantes de condición de refugio de este colectivo para la obtención de elementos probatorios. ${ }^{37}$ Es por ello, y siguiendo esta línea, por lo que la guía de la EASO dice que los tipos de pruebas admitidas son las orales (declaraciones del solicitante o de su familia, testigos y declaraciones de peritos), las pruebas documentales (documentos de identidad, informes médicos, decisiones judiciales, informes policiales, correos electrónicos, artículos de prensa...), las pruebas visuales (redes sociales, fotografías, videos, dibujos), las pruebas sonoras (grabaciones) y otras piezas (objetos, huellas digitales, cicatrices corporales...).

\section{Las pruebas prohibidas en las solicitudes de asilo} a la luz de la jurisprudencia del TJUE

En los últimos años algunos Estados han utilizado medios de prueba que han impresionado a la opinión pública, como los test falométricos que fueron inventados por el sexólogo Kurt Freund en 1950 para luchar contra las infracciones sexuales. Dicho test consiste en una técnica mecánica que permite medir la excitación sexual masculina en función del flujo sanguíneo genital en respuesta a una estimulación visual sexualmente explícita con

37 ACNUR, Manual y directrices sobre procedimientos y criterios para determinar la condición de refugiado en virtud de la Convención de 1951 y el Protocolo de 1967 sobre el Estatuto de los Refugiados, Ginebra, ACNUR, reedición de diciembre de 2011, p. 38. 
la ayuda de electrodos colocados en el pene. Concretamente, las autoridades checas hacían visualizar al solicitante un film pornográfico heterosexual para verificar si tenía o no una erección y, en función de dicho test, se le otorgaba o rechazaba el asilo. El ACNUR rápidamente condenó tal practica considerándola intrusiva y desproporcionada. ${ }^{38}$

Más tarde, y gracias a la iniciativa del Consejo de Estado holandés, el TJUE, por medio de una cuestión prejudicial, se pronunció sobre la conformidad de tal práctica y otras similares con el derecho europeo. ${ }^{39} \mathrm{El}$ problema surgió cuando las autoridades holandesas se encontraron ante solicitantes que voluntariamente deseaban someterse a un test falométrico o, en su defecto, proponían filmarse en una relación homosexual para probar su orientación sexual. ${ }^{40}$ La cuestión prejudicial dio ocasión al TJUE de recordar los principios que deben guiar el derecho de la prueba en materia de asilo fundado en la orientación sexual. Los jueces de Luxemburgo indican que las modalidades de apreciación de la prueba deben ser conforme al derecho de la UE y respetar los principios establecidos en la Carta, en particular el respeto a la dignidad humana y a la vida privada y familiar del solicitante. ${ }^{41}$

ElTJUE establece, asimismo, que no se deben evaluar las solicitudes de asilo sobre la base únicamente de nociones estereotipadas asociadas a la homosexualidad. Si las autoridades están legitimadas a proceder a interro-

38 UN High Commissionner for Refugees (UNHCR), UNHCR's Comments on the Practice of Phallometry in the Czech Republic to Determine the Credibility of Asylum Claims based on Persecution due to Sexual Orientation, New York, UNHCR, abril de 2011.

39 Sentencia del TJUE (Gran Sala), A y otros c. Staatssecretaris van Veiligheid..., cit.

40 Tres ciudadanos de países no comunitarios habían pedido asilo por temor a ser perseguidos por su homosexualidad. En los tres casos las autoridades holandesas denegaron las peticiones porque consideraron que la orientación no había quedado "demostrada". Uno de ellos — en una segunda petición - aseguró estar "dispuesto a practicar un acto homosexual" o a someterse a "exámenes". El segundo ciudadano llegó a presentar una grabación en video de actos íntimos con otra persona de su mismo sexo. El tercero no aportó "más detalles sobre sus sentimientos y el proceso interior relativo a su orientación”, según el criterio de las autoridades holandesas.

${ }^{41}$ En esta Sentencia, elTJCE considera que la protección subsidiaria prevista en el artículo 15 c) de la directiva 2004/83/CE representa una medida protectora más allá de la recogida en el artículo 3o. del CEDH, por lo que su interpretación debe realizarse de forma autónoma desde el derecho comunitario. Para más información, Dunne, Peter, " $A, B$ and $C$ v. Staatssecretaris van Veiligheid en Justitie: Fairer Assessment Procedures for Gay and Lesbian Asylum Applicants in the EU”, European Law Review, Londres, vol. 21, núm. 3, 2015, pp. 411-423. 
gatorios destinados a evaluar los hechos relevantes relativos a la orientación sexual del solicitante, las preguntas relativas a detalles íntimos acerca de la vida sexual son, según el TJUE, contrarias a los derechos fundamentales protegidos por la Carta y, particularmente, el derecho a la dignidad y a la privacidad.

Las fotos íntimas, los videos y los test tendentes a probar la orientación sexual del solicitante constituyen pruebas prohibidas que deben ser desestimadas in limine, inclusive si son propuestas o requeridas por el interesado. Por lo demás, el tribunal subraya que autorizar o aceptar este tipo de pruebas tendría un efecto incentivador respecto de otros solicitantes y equivaldría, de facto, a imponerles este tipo de pruebas. De igual modo, son prohibidos por el TJUE los test psicológicos de personalidad que pretenden probar la orientación sexual del solicitante.

En este orden de ideas, a causa de las decisiones adoptadas por las autoridades húngaras, el TJUE tendría la oportunidad de pronunciarse sobre este tema. Y es que, en 2015 la Oficina Húngara de Inmigración y Asilo (Bevándorlási és Állampolgársági Hivatal) decidió denegar el estatuto de refugiado a un solicitante sobre la base de un informe pericial psicológico según el cual no se podía determinar su homosexualidad. Los test utilizados por el perito fueron el test de Rorschach de evaluación psicológica de tipo proyectiva, que consiste en presentar unas láminas con manchas que deben ser interpretadas por el paciente, y el test de Szondi, que consiste en analizar una serie de fotos y organizarlas en función de las más agradables hacia las más desagradables. ${ }^{42}$ Esos diagnósticos carecen de base científica y han sido abandonados por los profesionales de Europa occidental, sin embargo, fueron utilizados en Hungría hasta esta sentencia.

En este caso, el solicitante apeló la decisión y las autoridades judiciales húngaras decidieron, mediante petición prejudicial, consultar al TJUE para saber si es posible evaluar las declaraciones del solicitante basándose en un test psicológico de personalidad y, de un modo general, informarse sobre qué tipo de peritaje se puede utilizar para examinar la credibilidad de los relatos de solicitudes de asilo en razón de la orientación sexual. ElTJUE, en la decisión F/ Bevándorlási és Állampolgársági Hivatal del 25 de enero 2018,

42 Fernández Dávila, Percy y Ávila, Daniel, "Indicadores de homosexualidad en el dibujo de la figura humana: comparación entre homosexuales y heterosexuales”, Revista de Psicología de la Pontificia Universidad Católica del Perú, Lima, vol. 21, núm. 2, 2003, pp. 333-361. 
comenzó su argumentación por la última pregunta, indicando que "algunos métodos periciales pueden resultar útiles para valorar hechos y circunstancias que consten en la solicitud y pueden aplicarse sin vulnerar los derechos fundamentales de dicho solicitante".

No obstante, respecto a la primera pregunta, los jueces de Luxemburgo concluyeron que incluso cuando la realización de los test psicológicos del informe pericial está subordinada a la expresión del consentimiento por parte del solicitante, "cabe considerar que dicho consentimiento no se presta necesariamente con libertad, dado que, de facto, viene impuesto por la presión de las circunstancias en las que se encuentran los solicitantes de protección internacional", ${ }^{43}$ y que, por tanto, en estas condiciones, utilizar un informe psicológico para determinar la orientación sexual del solicitante constituye una injerencia en el derecho al respeto de su vida privada. ${ }^{44}$

En conclusión, la gravedad de la injerencia no justifica el objetivo deseado: determinar la orientación sexual del solicitante. Según el Tribunal, dicho peritaje no resulta indispensable para evaluar las declaraciones del solicitante, y la entrevista con las autoridades del asilo resulta más adecuada a tal efecto. En este sentido, el Tribunal de Justicia señala que, en virtud de la directiva, ante una situación en la que la orientación sexual del solicitante no se recoge en pruebas documentales, las autoridades nacionales, que deben disponer de personal competente, pueden basarse, entre otras opciones, en la coherencia y la credibilidad de las declaraciones del solicitante. Además, el Tribunal subraya que

...en el mejor de los casos, el mencionado examen no tiene más que una fiabilidad limitada, por lo que puede cuestionarse su utilidad para evaluar la credibilidad de las declaraciones de un solicitante de asilo, especialmente en casos como el del presente asunto, en los que las declaraciones del solicitante no son contradictorias.

En estas circunstancias, el Tribunal de Justicia concluye que "la utilización de un examen psicológico con el fin de determinar la realidad de

43 Sentencia del Tribunal de Justicia (Sala Tercera), 25 de enero de 2018, apartado 53. Planteamiento éste que también mantuvo en su sentencia del 2 de diciembre de 2014, A. y otros, C-148/13 a C-150/13, EU:C:2014:2406, apartado 66.

44 Sentencia del Tribunal de Justicia (Sala Tercera), 25 de enero de 2018, apartados 54, 56 y 57. 
la orientación sexual de un solicitante de asilo no se ajusta a la directiva leída a la luz de la Carta". ${ }^{45}$

\author{
VIII. CRITERIOS PARA LA EVALUACIÓN
}

DE LA CREDIBILIDAD DE LAS DECLARACIONES

\author{
DEL SOLICITANTE
}

La obtención del asilo dependerá, en gran medida, de la credibilidad de las declaraciones del solicitante, sobre todo cuando las mismas constituyen el único elemento de prueba. Una vez identificados los hechos pertinentes; el solicitante tenga un temor fundado de ser perseguido en su país de origen en razón de su homosexualidad (verdadera o supuesta) y que se encuentre en la incapacidad de solicitar la protección de su país (bien porque no pueda, bien porque no desee hacerlo por dicho temor), la cuestión de la evaluación de la credibilidad de sus declaraciones por parte de las autoridades de instrucción constituye la etapa más importante del procedimiento de asilo.

Evaluar la credibilidad exige que el agente responsable de la decisión establezca una conclusión clara acerca de la probable veracidad de cada hecho invocado. La cuestión es particularmente compleja, ya que tanto la directiva de 2011 como la de 2013 no prevén la manera en cómo se debe evaluar la credibilidad de dicha declaración. Corresponde entonces a cada Estado miembro regular en su propio ordenamiento jurídico las modalidades procesales del caso. Para ello, el ACNUR propone una definición de la credibilidad, según la cual la misma puede establecerse "cuando el solicitante ha presentado una solicitud coherente y verosímil, que no contradice hechos de conocimiento público y que, por lo tanto, en su conjunto, puede resultar creíble". ${ }^{46}$

Sobre la base de lo establecido por las diferentes jurisprudencias nacionales, el EASO, en su documento de 2018 sobre la valoración de las pruebas y de la credibilidad en el marco del sistema europeo común de asilo,

45 TJUE, comunicado de prensa núm. 8/18, 25 de enero de 2018, relativo a la sentencia en el asunto C-473/16, F c. Bevándorlási és Állampolgársági Hivatal.

46 ACNUR, Nota sobre la carga y el mérito..., cit., p. 2. 
propone determinados criterios que permiten evaluar la credibilidad de la declaración del solicitante en función de cuatro variables: la consistencia interna del relato, la externa, su grado de detalle y su verosimilitud.

Según el EASO, la consistencia interna se refiere a las conclusiones acerca de la coherencia y las posibles incongruencias, discrepancias u omisiones de las declaraciones y otras pruebas presentadas por los solicitantes en sus escritos y entrevistas, en todas las fases de la tramitación de su solicitud y recurso hasta la resolución final. Lo principal en este aspecto es el nivel de coherencia del relato o historia del solicitante. ${ }^{47}$ Ello no significa, como lo recuerda el TJUE, que el relato deba ser lineal, cronológico y que el solicitante deba recordar con lujo de detalle fechas exactas $;{ }^{48}$ como siempre, todo dependerá de las circunstancias individuales. Por su parte, la consistencia externa se refiere

... a la coherencia entre el relato del solicitante (expuesto en su entrevista personal y otras declaraciones) y la información de conocimiento general, otras pruebas, como testimonios presentados por familiares u otros testigos, pruebas documentales de carácter médico y documental sobre cuestiones relevantes para la solicitud, $\mathrm{IPO}^{49}$ y cualquier otra prueba pertinente sobre el país.

El nivel de detalle suficiente como índice de valoración de la credibilidad del relato significa que es razonable esperar que el solicitante pueda restituir los hechos mas significativos de manera específica teniendo en cuenta siempre las circunstancias individuales del caso. Muchas veces la imposibilidad de reconstruir detalladamente un hecho o de hacerlo de manera muy distante constituyen mecanismos de defensa inconscientes que permiten proteger emocionalmente al solicitante de los traumas vividos. ${ }^{50}$ Respecto de la verosimilitud del relato, el EASO afirma que el término verosímil tiene un alcance mucho más limitado que el de credibilidad, ya que un relato

47 EASO, Évaluation des éléments de preuve et de la crédibilité dans le contexte du régime d'asile européen commun, Luxemburg, Office des Publications de l'Union Européenne, 2018, p. 90.

48 European Court of Human Rights (GC), Case of J.K. and Others v. Sweden. Application núm. 59166/12, apartado 93.

49 IPO significa "información sobre país de origen”.

50 Freedman, Jane, "Peur, honte, humiliation? Les émotions complexes des demandeurs d'asile et des réfugiés en Europe”, Revue Migrations Société, París, vol. 2, núm. 168, 2017, pp. 23-34. 
puede no ser creíble, a pesar de ser verosímil. El ACNUR considera que la verosimilitud se refiere a lo que parece razonable, posible o probable.

Otro elemento importante en el momento de valorar la credibilidad es lo establecido por el TJUE en su decisión de diciembre de 2014, respecto a la exigencia de no evaluar las declaraciones del solicitante únicamente sobre la base de las concepciones o preguntas estereotipadas acerca de la homosexualidad. Los estereotipos son representaciones mentales que simplifican la complejidad de los grupos o las personas a las que se les aplica. Preguntar a un solicitante si conoce las discotecas gais del país de acogida es presumir que todos los homosexuales acuden a dichos recintos, o considerar que una mujer no puede ser lesbiana porque esté casada y tiene hijos significa ignorar la imposibilidad de muchas mujeres de mantenerse solteras en sus sociedades de origen. Del mismo modo, representar la orientación sexual como una progresión lineal que va de la ausencia de autoestima a una aceptación liberadora que culmina necesariamente en la "salida del armario" del solicitante constituye una visión estereotipada, pues se refiere a contornos urbanos occidentales y no corresponde necesariamente con otros contextos culturales.

Es importante señalar que en el momento de evaluar las declaraciones $y$, en general, todas las pruebas del procedimiento de asilo es importante hacerlo a partir de un enfoque multidisciplinar en el que intervienen materias como la sociología, los estudios de género, la antropología cultural y los estudios post coloniales, pues de lo contrario se corre el riesgo de considerar, en el momento de evaluar las pruebas, que la diferencia entre la homosexualidad y la heterosexualidad es la misma en el país de acogida que en el país de origen. Varios estudios han alertado del riesgo de imponer conceptos occidentales a las realidades no occidentales, ${ }^{51}$ por ello es necesario que las autoridades competentes en materia de asilo sean formadas de tal modo que puedan comprender la complejidad de la sexualidad en contextos distintos de los que están habituadas a actuar. ${ }^{52}$ Muchas veces la dificultad que tienen los solicitantes en hablar de su sexualidad es considerada por el instructor del procedimiento como una ausencia de detalle o una in-

51 Awondo, Patrick et al., "Une Afrique homophobe? Sur quelques trajectoires de politisation de l'homosexualité Cameroun, Ouganda, Sénégal et Afrique du Sud”, Raisons Politiques, París, núm. 49, 2013, pp. 95-118.

52 Borrillo, Daniel, “Droit d'asile des minorités sexuelles: gare à l'ethnocentrisme”, Le Monde, 4 de marzo de 2018, p. 16. 
coherencia en el relato, sin entender que muchas culturas simplemente no verbalizan la sexualidad como lo hace la nuestra o no le han puesto palabras a determinadas cuestiones sexuales, como hemos hecho en Occidente. ${ }^{53}$ Del mismo modo, como lo ha demostrado J. Díaz Lafuente, en los países árabes la homosexualidad refleja relaciones de poder en las que se establece una diferenciación jerárquica entre el papel sexual activo y el pasivo, asociados respectivamente al varón y a la mujer. En ese sentido, la situación de un hombre adulto que mantiene una relación sexual con uno más joven no implica una aceptación social de "relaciones afectivas duraderas y estables entre personas del mismo sexo". ${ }^{54}$

\section{CONCLUSIÓN}

En los procesos de concesión de asilo por razones de orientación sexual e identidad de género, el razonamiento probatorio del juez le lleva a decidir en función de su íntima convicción con base en varios indicios y partiendo del análisis de las diferentes informaciones e indicaciones de las que dispone. Ahora bien, el que la valoración y evaluación de las pruebas en estos procesos estén sujetas al principio de la libre apreciación no significa, como lo hemos intentado demostrar, que no existan límites. Aunque resulte utópico, y hasta peligroso, establecer criterios objetivos que dirijan la íntima convicción de quien decide el asilo, es necesario prevenir la arbitrariedad.

La orientación sexual como riesgo de persecución y, por tanto, causa para la obtención de asilo, lleva aparejada la dificultad de su credibilidad, la cual depende, en gran medida, de las pruebas aportadas y de las declaraciones del solicitante. Dificultad que, en parte, se explica por la inexistencia de disposiciones en el ámbito de la UE que prevean el modo de evaluación en estos casos. Es, por tanto, cada Estado miembro el que determina la regulación de las modalidades procesales del caso en la práctica.

53 Dayan-Herzbrun, Sonia y Tassadit, Yacine (coords.), Tumultes. Dire les homosexualités d'une rive à l'autre de la Méditerranée, París, Kimé, 2013.

54 Díaz Lafuente, J., Refugio y asilo por motivos de orientación sexual y / o identidad de género en el ordenamiento constitucional español, tesis doctoral, Valencia, Universidad de Valencia, pp. 76 y 77. 
Ante esta situación, la EASO propone determinados criterios de evaluación, entre los que pueden citarse la consistencia interna del relato, su consistencia externa, el grado de detalle y su verosimilitud. En este orden de ideas, elTJUE, como intérprete del derecho de la UE, también ha establecido, a través de su jurisprudencia, una serie de principios-guía que deben seguir las autoridades competentes, como el respeto a la Carta de Derechos Fundamentales de la UE en los procesos de apreciación de las pruebas o la prohibición de investigaciones corporales (test falométrico u otros), así como de test psicológicos de personalidad (Szondi, Rorschach...), que sean invasivos de la dignidad de los solicitantes y de su intimidad.

En definitiva, con el presente artículo hemos intentado, modestamente, presentar de manera sistemática algunos elementos procesales necesarios para evitar que la convicción íntima de quien decide el futuro de una persona que solicita el asilo por motivo de orientación sexual o identidad de género se funde únicamente en una apreciación subjetiva, sino más bien, que pueda construirse en función de los elementos o criterios objetivos propuestos por las diferentes instituciones europeas.

\section{Bibliografía}

ACNUR, Directrices sobre protección internacional. La persecución por motivos de género en el contexto del artículo 1A (2) de la Convención de 1951 sobre el Estatuto de los Refugiados y/o su Protocolo de 1967 (HCR/GIP/02/0), Ginebra, ACNUR, 7 de mayo de 2002.

ACNUR, Directrices sobre protección internacional núm. 9, Solicitudes de la condición de refugiado relacionadas con la orientación sexual y/o la identidad de género en el contexto del artículo $1 \mathrm{~A}$ (2) de la Convención sobre el Estatuto de los Refugiados de 1951 y/o su Protocolo de 1967, Ginebra, ACNUR, 2012.

ACNUR, Manual y directrices sobre procedimientos y criterios para determinar la condición de refugiado en virtud de la Convención de 1951 y el Protocolo de 1967 sobre el Estatuto de los Refugiados, Ginebra, ACNUR, reedición de diciembre de 2011. 
ACNUR, Nota de orientación sobre las solicitudes de la condición de refugiado relacionadas con la orientación sexual y la identidad de género, trad. de Unidad Legal Regional del Bureau de las Américas, Ginebra, ACNUR, noviembre de 2008.

ACNUR, Nota sobre la carga y el mérito de la prueba en las solicitudes de asilo, Ginebra, ACNUR, 16 de diciembre de 1998.

ACNUR, Protección de las personas con orientación sexual e identidad de género diversas. Informe mundial sobre los esfuerzos del ACNUR para proteger a solicitantes de asilo y refugiados lesbianas, gais, bisexuales, transgénero e intersex, Ginebra, ACNUR, diciembre de 2015.

Amnesty International, Mapping Anti-Gay Laws in Africa, Londres, Amnesty International UK, 31 de mayo de 2018.

AWONDO, Patrick et al., "Une Afrique homophobe? Sur quelques trajectoires de politisation de l'homosexualité Cameroun, Ouganda, Sénégal et Afrique du Sud", Raisons Politiques, París, núm. 49, 2013.

Borrillo, Daniel, "Droit d'asile des minorités sexuelles: gare à l'ethnocentrisme", Le Monde, 4 de marzo de 2018.

CHEMin, Anne, "L'asile, un naufrage européen”, Europe Solidaire Sans Frontières, París, octubre de 2015.

CONSEJO DE DERECHOS HumANOS, Informe del experto independiente sobre la protección contra la violencia y la discriminación por motivos de orientación sexual o identidad de género, Naciones Unidas, 19 de abril de 2017, 35o. periodo de sesiones.

DAyAn-HerzBrun, Sonia y TASSADIT, Yacine (coords.), Tumultes. Dire les homosexualités d'une rive à l'autre de la Méditerranée, París, Kimé, 2013.

Díaz LAFUENTE, J., Asilo y refugio por motivos de orientación sexual e identidad de género, Madrid, Congreso de los Diputados, 2016.

DíAz LAFUENTE, J., "El derecho de asilo por motivos de orientación sexual e identidad de género", Revista de Derecho Político, Madrid, núm. 89, enero-abril de 2014.

DunNe, Peter, " $A, B$ and $C$ v. Staatssecretaris van Veiligheid en Justitie: Fairer Assessment Procedures for Gay and Lesbian Asylum Applicants in the EU", European Law Review, Londres, vol. 21, núm. 3, 2015.

EASO, Évaluation des éléments de preuve et de la crédibilité dans le contexte du régime d'asile européen commun, Luxemburg, Office des Publications de l'Union Européenne, 2018. 
FERnÁndez DÁvila, Percy y Ávila, Daniel, "Indicadores de homosexualidad en el dibujo de la figura humana: comparación entre homosexuales y heterosexuales", Revista de Psicología de la Pontificia Universidad Católica del Perú, Lima, vol. 21, núm. 2, 2003.

FRA, Manual de derecho europeo sobre asilo, fronteras e inmigración, Luxemburgo, Oficina de Publicaciones de la Agencia de los Derechos Fundamentales de la Unión Europea, 2014.

FREEDMAN, Jane, "Peur, honte, humiliation? Les émotions complexes des demandeurs d'asile et des réfugiés en Europe", Revue Migrations Société, París, vol. 2, núm. 168, 2017.

Gortázar Rotaeche, Cristina, Derecho de asilo y "no rechazo” del refugiado, Madrid, Dykinson, 1996.

GraHL-MADSEN, Atle, "The European Tradition of Asylum and the Development of Refugee Law", Journal of Peace Research, Leyden, vol. 3, núm. 3, 1966.

LÉVY-BRUHL, Henri, "Réflexions sur la preuve judiciaire”, Journal de Psychologie Normale et Pathologique, París, vol. XLV, 1951.

ROMBOLI, Roberto, "La homosexualidad como elemento de discriminación: principios constitucionales y jurisprudencia de los jueces constitucionales y de las Cortes europeas", en CUESTA López, Víctor y SANTANA VEGA, Dulce M. (coords.), Estado de derecho y discriminación por razón de género, orientación e identidad sexual, Las Palmas de Gran Canaria, Servicio de Publicaciones y Difusión Científica de la ULPGC-Aranzadi, 2014.

Santolaya MachetTi, Pablo y PÉreZ-Moneo, Miguel Agapito, El derecho de asilo en la jurisprudencia (julio 2005-junio 2006), Barcelona, CIBOD, 2006.

TISSIER-RAFFIN, Marion, “L'orientation sexuelle comme motif de persécution doit être appréciée dans la dignité", La Revue des Droits de L'homme, París, núm. 28, enero de 2015.

TuRner Hamilton, Cuthbert, Ecclesiae occidentalis monumenta antiquissima. Canonum et conciliorum graecorum interpretationes latinae, Exeter, Forgotten Books, 2018.

UNHCR, UNHCR's Comments on the Practice of Phallometry in the Czech Republic to Determine the Credibility of Asylum Claims based on Persecution due to Sexual Orientation, New York, UNHCR, abril de 2011. 